\title{
PERKEMBANGAN PSIKOMOTORIK PESERTA DIDIK DI KOTA METRO
}

\author{
Triana Asih \\ Pendidikan Biologi Universitas Muhammadiyah Metro \\ E-mail: asih.triana@yahoo.com
}

\begin{abstract}
:
The purpose of this study describes learning activities that are appropriate to the psychomotor taxonomy level of students from various levels of education so that teachers better understand the psychomotor taxonomy class in accordance with the ideal theory. This research was conducted using a qualitative method, with the subject this research consisting samples of students level psychomotor development in metro city. The object seen in this study is the psychomotor development of students. The procedure of this study consists of 3 stages; 1) Making work guidelines for observers in the form of student development modules. 2) Data collection. 3) Processing of observational data. Psychomotor activities that are applied in the learning process and in accordance with psychomotor development are Level 2 and 3; namely 1) manipulation (P2) is an activity aid that has never been seen before about guidelines or instructions. Indicators that attend (P2) make / communicate a work. 2) experience (naturalization) (P3) is the ability to carry out reflex activities, namely physical facilitating activities that improve work efficiency. indicators taken (P3) Learning models that can develop P2 level psychology models are vocational and cooperative learning models, for P3 psychomotor models can be developed using peer tutoring learning models.
\end{abstract}

Kata Kunci: Tingkat Psikomotorik, KKO, Peserta didik.

\section{PENDAHULUAN}

Kurangnya optimalisasi sistem pendidikan di Indonesia penyebabnya antara lain kurangnya materi pengembangan psikomotor untuk tenanga pendidik, dan kurangnya kualitas pendidik dalam transformasi ilmu kepeda peserta didik (Aziz et.al., 2017). Sertifikasi guru yang diharapkan dapat meningkatkan kompetensi kualitas guru lebih diutamakan untuk pencukupan waktu beban mengajar saja, seharusnya guru lebih mengembangkan kompetensinya dengan mengikuti pelatihan-pelatihan pengembangan kompetensi mengajarnya
Standar

penilaian Permendikbud tahun 2016 no 22 tentang standar proses dan no 23 tentang standar penilaian harus benarbenar dipenuhi dengan memahami penerapan kurikulum yang berlaku, memahami bagaimana proses yang sebenar-benarnya dan bagaimana cara menilai kompetensi afektif, kognitif dan psikomotor dengan valid dan reliabel. Pengembangan perangkat penilaian yang sering dianggap sulit yaitu kompetensi psikomotor, guru haru menyiapkan instrumen penliaian yang sesuai seperti lembar observasi.

Pembuatan lembar observasi psikomotorik peserta didik dapat dikembangkan jika guru memahami 
apa saja kegiatan-kegiatan yang dapat mengembangkan keterampilan psikomotor. Asih (2018), memaparkan penilaian hasil belajar psikomotor mencakup persiapan, proses, dan produk. Penilaian dapat dilakukan pada saat proses berlangsung yaitu pada waktu peserta didik melakukan praktik, atau sesudah proses berlangsung dengan cara mengetes peserta didik salah satunya melalui laporan hasil praktikum.

Penilaian yang dapat dilakukan pada saat proses berlangsung atau praktikum adalah lembar observasi. Lembar observasi dikembangan dengan mengetahui tingkatan-tingkatan taksonomi ranah psikomotorik. Dalam buku yang dikembangkan Asih (2018) Kata Kerja Oprasional (KKO) psikomotor yang digunakan dalam kurikulum 2013 revisi terdiri dari 4 tingkatan, Yang pertama, Imitasi (meniru) adalah kemampuan melakukan kegiatan-kegiatan sederhana dan sama persis dengan yang dilihat atau yang diperlihatkan sebelumnya. Ke$d u a$, manipulasi adalah kemampuan melakukan kegiatan sederhana yang belum pernah dilihat sebelumnya tetapi berdasarkan pedoman atau petunjuk saja. Ke-tiga, pengalamiahan (naturalisasi) adalah kemampuan melakukan kegiatan secara refleks, yakni kegiatan yang melibatkan fisik saja sehingga efektivitas kerja tinggi. Ke-empat artikulasi adalah kemampuan melakukan kegiatan yang kompleks dan tepat, sehingga hasil kerjanya merupakan sesuatu yang utuh.

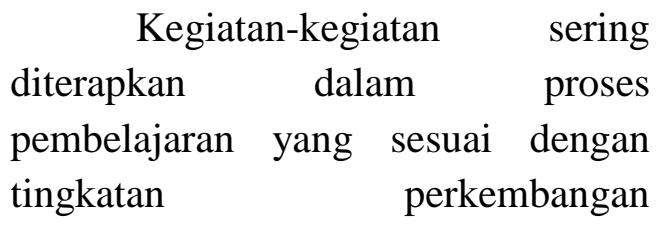
psikomotorik belum banyak dipahami oleh para guru. Penelitian ini bertujuan memaparkan kegiatankegiatan pembelajaran yang sesuai dengan tingkatan taksonomi psikomotorik perserta didik dari berbagai jenjang pendidikan agar guru lebih memahami tingkatan taksonomi psikomotorik sesuai dengan teori yang ideal. Maanfaat penelitian ini membantu pendidik terutama guru dapat mengembangkan kegiatatan psikomotorik peserta didik dalam proses pembelajaran dengan mendesain Rencana Pelaksanaan Pembelajaran dan instrumen penilaian psikomotorik sesuai dengan indikator yang dikembangkan berdasarkan teori tingktan psikomotor peserta didik dengan tepat.

\section{METODE}

Penelitian ini menggunakan metode kualitatif, dengan subjek penelitian yang terdiri dari beberapa sampel peserta didik jenjang TK, SD, SMP, SMA yang ada di kota Metro. Objek yang diamati dalam penelitian ini adalah perkembangan psikomotor peserta didik. Prosedur penelitian ini terdiri dari 3 tahapan;. 1) Pembuatan petunjuk kerja untuk observer berupa modul pengamatan perkembangan peserta didik. Pembuatan modul pengamatan perkembangan psikomotorik peserta didik ini 
terfokus pada dua indikator pengamatan yaitu indikator yang mengarah pada tingkatan taksonomi Bloom ke-2 dan ke-3;

2) Pengumpulan data, tahapan ini dilakukan selama 3 minggu untuk mendapatkan data yang diingikan. Pengumpulan data dilakukan dengan cara observasi dan wawancara, observer adalah Mahasiswa Pendidikan Biologi Semester 2 yang sedang menempuh mata kuliah Perkembangan Peserta Didik, 1 sampel peserta didik akan di observasi oleh 1 observer; 3) Pengolahan data hasil pengamatan. Hasil pengamatan perkembangan psikomotorik peserta didik akan di olah ke dalam tabel pengamatan perjenjang. Hasil deskripsi pengamatan kemudian di masukan dalam skala penilaian dan di rekapitulasi ke dalam persentase kriteria penilaian.

\section{HASIL DAN PEMBAHASAN}

Penelitian ini memokuskan pada dua indikator pengamatan yaitu indikator yang mengarah pada tingkatan taksonomi Bloom ke-2 dan ke-3. Tingkatan kedua yaitu manipulasi (P2) adalah kemampuan melakukan kegiatan sederhana yang belum pernah dilihat sebelumnya tetapi berdasarkan pedoman atau petunjuk saja. KKO yang sering digunakan adalah mengkomunikasikan,

mendemonstrasikan, membuat, melatih, dan merancang dll. Tingkatan ketiga pengalamiahan (naturalisasi) (P3) adalah kemampuan melakukan kegiatan secara refleks, yakni kegiatan yang melibatkan fisik saja sehingga efektivitas kerja tinggi. KKO yang sering digunakan mengoperasikan, memindahkan, mendorong, menarik dll. Indikator yang diamati (P2) membuat/mengkomunikasikan suatu karya dan (P3) Mengoperasikan suatu alat/benda. Rincian kegiatan hasil pengamatan per jenjang lebih jelasnya dapat dilihat pada tabel di bawah ini.

Tabel 1. Pengamatan Perkembangan Kognitif pra-sekolah Taman Kanak Kota Metro

\begin{tabular}{|c|c|c|c|}
\hline No. & Identitas & Deskripsi Hasil Observasi & Skor \\
\hline \multirow[t]{6}{*}{1} & $\begin{array}{l}\text { Dani Rizky } \\
\text { Pratama, } 6 \text { tahun, } \\
\text { TK Asyiyah Iring }\end{array}$ & $\begin{array}{l}\text { Observasi 1, Mampu menulisdengan baik tanpa keluar } \\
\text { dari garis-garis buku tulis dan tulisan yang dibuat sama } \\
\text { dengan yang dicontohkan ibu guru (P2). }\end{array}$ & 4 \\
\hline & $\begin{array}{l}\text { Mulyo } \quad \text { Metro } \\
\text { Timur. }\end{array}$ & $\begin{array}{l}\text { Mampu menyusun mainan balok kayu membentuk } \\
\text { bangunan masjid dengan baik (P3) }\end{array}$ & 4 \\
\hline & & $\begin{array}{l}\text { Observasi 2, Sudah bisa mewargai gambar hewan dan } \\
\text { tumbuhan namun belum sesuai dengan realita warna } \\
\text { gambar pada kenyataan dan masih keluar garis dalam } \\
\text { mewarnai (P2). }\end{array}$ & 3 \\
\hline & & Mampu menyusun mainan bongkar susun (P3) & 4 \\
\hline & & $\begin{array}{l}\text { Observasi 3, Mampu menulis dan mewarnai dengan baik } \\
\text { (P2). }\end{array}$ & 4 \\
\hline & & $\begin{array}{l}\text { Mampu menyusun mainan balok kayu membentuk } \\
\text { bangunan masjid dengan baik (P3). }\end{array}$ & 4 \\
\hline 2 & $\begin{array}{l}\text { Keyla Oktalivia } \\
\text { Huda, } 6 \text { tahun, } \\
\text { TK Asyiyah Iring }\end{array}$ & $\begin{array}{l}\text { Observasi 1, Mampu menulis dengan baik, namun } \\
\text { tulisan belum rapih masih naik turun tetapi tidak keluar } \\
\text { garis dan sama seperti yang dicontohkan ibu guru (P2). }\end{array}$ & 3 \\
\hline
\end{tabular}




\begin{tabular}{|c|c|c|c|}
\hline & \multirow[t]{5}{*}{$\begin{array}{l}\text { Mulyo Metro } \\
\text { Timur. }\end{array}$} & $\begin{array}{l}\text { Mampu mengapus tulisan yang salah menggunakan } \\
\text { penghapus dengan baik (P3) }\end{array}$ & 4 \\
\hline & & $\begin{array}{l}\text { Observasi 2, Bisa mewargai gambar hewan dan } \\
\text { tumbuhan namun belum sesuai dengan realita warna } \\
\text { gambar pada kenyataan dan masih keluar garis (P2). }\end{array}$ & 3 \\
\hline & & Mampu menyusun mainan bongkar pasang (P3) & 4 \\
\hline & & $\begin{array}{l}\text { Observasi 3, Mampu menulis dengan baik, namun } \\
\text { tulisan belum rapih masih naik turun tetapi tidak keluar } \\
\text { garis dan sama seperti yang dicontohkan ibu guru (P2). }\end{array}$ & 3 \\
\hline & & $\begin{array}{l}\text { Mampu menggunakan alat makan seperti sendok dan } \\
\text { garpu serta memakan makanan dengan baik (P3) }\end{array}$ & 4 \\
\hline \multirow[t]{6}{*}{3} & \multirow{6}{*}{$\begin{array}{l}\text { Diyah Kusuma } \\
\text { Nothy, } 5 \text { tahun, } \\
\text { TK Asyiyah Iring } \\
\text { Mulyo Metro } \\
\text { Timur. }\end{array}$} & $\begin{array}{l}\text { Observasi 1, Bisa mewarnai, namun warna belum sesuai } \\
\text { dengan objek nyata, dan masih keluar (P2). }\end{array}$ & 3 \\
\hline & & Mampu membuat tongkat dari lego (P3). & 4 \\
\hline & & $\begin{array}{l}\text { Observasi 2, Bisa mewarnai, namun warna belum sesuai } \\
\text { dengan objek nyata, dan masih keluar }(\mathrm{P} 2) \text {. }\end{array}$ & 3 \\
\hline & & Mampu membuat miniatur rumah dari lego (P3) & 4 \\
\hline & & $\begin{array}{l}\text { Observasi 3, Bisa mewarnai, namun warna belum sesuai } \\
\text { dengan objek nyata (P2) }\end{array}$ & 3 \\
\hline & & Mampu membaca lancar tanpa perlu mengeja (P3) & 4 \\
\hline \multirow[t]{8}{*}{4} & \multirow{6}{*}{$\begin{array}{l}\text { Aqila Irawan, } 5 \\
\text { tahun, TK PGRI } \\
\text { As-Syifa Metro }\end{array}$} & $\begin{array}{l}\text { Observasi 1, Bisa mewarnai pelanggi tetapi kurang rapih } \\
\text { (P2) }\end{array}$ & 3 \\
\hline & & Bisa menyusun kembali bongkar pasang (P3) & 4 \\
\hline & & $\begin{array}{l}\text { Observasi 2, Bisa menulis latin dengan lancar dan baik } \\
(\mathrm{P} 2) \text {. }\end{array}$ & 4 \\
\hline & & Bisa menyusun lego menjadi miniatur rumah & 4 \\
\hline & & $\begin{array}{l}\text { Observasi 3, Bisa mewarnai pemandangan dengan baik } \\
(\mathrm{P} 2) \text {. }\end{array}$ & 4 \\
\hline & & Bisa menyusun balok menjadi pintu (P3) & 4 \\
\hline & & Rata-Rata & 3,67 \\
\hline & & Persentase & $\begin{array}{l}91 \\
75 \%\end{array}$ \\
\hline
\end{tabular}

Tabel 2. Pengamatan Perkembangan Psikomotorik pada Jenjang Sekolah Dasar Kota Metro

\begin{tabular}{|c|c|c|c|}
\hline No. & Identitas & Deskripsi Hasil Observasi & Skor \\
\hline \multirow[t]{7}{*}{1} & \multirow{7}{*}{$\begin{array}{l}\text { anda Bunga } \\
\text { Rahmadani, } 11 \\
\text { tahun, SD Negri } 5 \\
\text { Metro. }\end{array}$} & Observasi 1, Membuat karangan tulisan dengan bertanya & 3 \\
\hline & & kepada guru (P2) & \\
\hline & & Mampu menyanyikan lagu-lagu daerah dengan baik (P3) & 4 \\
\hline & & $\begin{array}{l}\text { Observasi 2, Mampu memberi tanggapan dengan baik } \\
\text { saat diskusi (P2) }\end{array}$ & 4 \\
\hline & & Mampu bermain bola kasti seperti dengan baik (P3) & 4 \\
\hline & & $\begin{array}{l}\text { Observasi 3, Membuat karangan tulisan dengan baik } \\
\text { (P2) }\end{array}$ & 4 \\
\hline & & $\begin{array}{l}\text { Mampu melakukan tantangan saat di beri tantangan } \\
\text { untuk menari (P3) }\end{array}$ & 4 \\
\hline \multirow[t]{4}{*}{2} & \multirow{4}{*}{$\begin{array}{l}\text { Kenzi Gibran } \\
\text { Rabbani, } 8 \text { tahun, } \\
\text { SD Negri } 5 \\
\text { Metro. }\end{array}$} & $\begin{array}{l}\text { Observasi 1, Mampu memberi tanggapan walaupun } \\
\text { belum lancar dan malu-malu (P2) }\end{array}$ & 3 \\
\hline & & $\begin{array}{l}\text { Dapat bermain bulu tangkis walaupun belum terlalu } \\
\text { mahir (P3) }\end{array}$ & 2 \\
\hline & & $\begin{array}{l}\text { Observasi 2, membuat karangan tulisan tetapi belum } \\
\text { rapih (P2) }\end{array}$ & 3 \\
\hline & & $\begin{array}{l}\text { Menyanyikan lagu-lagu daerah dengan lumayan baik } \\
\text { tetapi banyak yang belum hafal (P3) }\end{array}$ & 3 \\
\hline
\end{tabular}




\begin{tabular}{|c|c|c|c|}
\hline & & $\begin{array}{l}\text { Observasi 3, Memberikan tanggapan dengan baik saat } \\
\text { diskusi (P2). }\end{array}$ & 4 \\
\hline & & Bermain bulu tangkis sudah sedikit lancar (P3) & 3 \\
\hline \multirow[t]{6}{*}{3} & \multirow{6}{*}{$\begin{array}{l}\text { M. Rasya Al } \\
\text { Azzam Wijaya, } \\
10 \text { tahun, SD } \\
\text { Muhammadiyah } \\
\text { Metro Pusat. }\end{array}$} & $\begin{array}{l}\text { Observasi 1, Mampu memberi tanggapan tetapi belum } \\
\text { lugas dan lancar (P2) }\end{array}$ & 3 \\
\hline & & Dapat bermain sepak bola dengan lincah (P3) & 4 \\
\hline & & $\begin{array}{l}\text { Observasi 2, Mengerjakan tugas dengan tetapi belum } \\
\text { terlalu benar }(\mathrm{P} 2)\end{array}$ & 3 \\
\hline & & $\begin{array}{l}\text { Dapat menulis aksara lampung dengan baik dan benar } \\
\text { (P3) }\end{array}$ & 4 \\
\hline & & $\begin{array}{l}\text { Observasi 3, Dapat menggambar dengan bagus tapi } \\
\text { masih meniru temannya (P2) }\end{array}$ & 3 \\
\hline & & Dapat bermain sepak bola dengan lincah (P3) & 4 \\
\hline \multirow[t]{6}{*}{4} & \multirow{6}{*}{$\begin{array}{l}\text { Dinda } \\
\text { Nurhasanah, } 11 \\
\text { tahun, SD } \\
\text { Muhammadiyah } \\
\text { Metro Pusat. }\end{array}$} & $\begin{array}{l}\text { Observasi 1, Mengerjakan tugas dengan baik dan benar } \\
\text { (P2) }\end{array}$ & 4 \\
\hline & & $\begin{array}{l}\text { Dapat membacakan ayat-ayat Al-Quran dengan baik dan } \\
\text { benar (P3) }\end{array}$ & 4 \\
\hline & & $\begin{array}{l}\text { Observasi 2, Dapat menggambar dengan bagus dan } \\
\text { benar (P2) }\end{array}$ & 4 \\
\hline & & $\begin{array}{l}\text { Dapat menulis aksara lampung dengan baik dan benar } \\
\text { (P3) }\end{array}$ & 4 \\
\hline & & $\begin{array}{l}\text { Observasi 3, Mengerjakan tugas dengan baik dan benar } \\
\text { (P2) }\end{array}$ & 4 \\
\hline & & Dapat bermain bola kasti dengan baik dan lincah (P3) & 4 \\
\hline \multirow[t]{6}{*}{5} & \multirow{6}{*}{$\begin{array}{l}\text { Fadil Pasha } \\
\text { Dinata, } 12 \text { tahun, } \\
\text { SD N } 1 \text { Metro } \\
\text { Timur. }\end{array}$} & $\begin{array}{l}\text { Observasi 1, Mampu menyebutkan nama-nama pelanet } \\
\text { secara urut (P2) }\end{array}$ & 4 \\
\hline & & $\begin{array}{l}\text { Menggunakan spidol dan menulis di papan tulis dengan } \\
\text { jelas tetapi belum rapih }(\mathrm{P} 3)\end{array}$ & 3 \\
\hline & & $\begin{array}{l}\text { Observasi 2, Mampu menyebutkan Pancasila dengan } \\
\text { lancar dan benar (P2) }\end{array}$ & 4 \\
\hline & & Menggunakan pemukul bola kasti dengan benar (P3) & 4 \\
\hline & & $\begin{array}{l}\text { Observasi 3, Menyelesaikan tugas prakarya dengan baik } \\
(\mathrm{P} 2)\end{array}$ & 4 \\
\hline & & $\begin{array}{l}\text { Menulis aksara lampung di papan tulis dengan benar } \\
\text { tetapi kurang rapih (P3) }\end{array}$ & 3 \\
\hline \multirow[t]{8}{*}{6} & \multirow{6}{*}{$\begin{array}{l}\text { Khairan Anam, } \\
10 \text { tahun, SD N } 1 \\
\text { Metro Timur. }\end{array}$} & $\begin{array}{l}\text { Observasi 1, menyebutkan pancasila dengan lancar dan } \\
\text { lugas (P2) }\end{array}$ & 4 \\
\hline & & $\begin{array}{l}\text { Menggunakan spidol dan menulis aksara lampung di } \\
\text { papan tulis dengan jelas rapih (P3) }\end{array}$ & 4 \\
\hline & & $\begin{array}{l}\text { Observasi 2, Menyelesaikan tugas prakarya cukup baik } \\
\text { (P2) }\end{array}$ & 3 \\
\hline & & Dapat bermain bola voli dengan baik (P3) & 4 \\
\hline & & Observasi 3, Membuat tugas prakarya cukuo baik (P2) & 3 \\
\hline & & $\begin{array}{l}\text { Menggunakan pemukul bola kasti dengan benar tetapi } \\
\text { kadang bola kasti tidak terpukul (P3) }\end{array}$ & 3 \\
\hline & & Rata-Rata & 3,58 \\
\hline & \multicolumn{2}{|r|}{ Persentase } & $\begin{array}{c}89,5 \\
\%\end{array}$ \\
\hline
\end{tabular}


Tabel 3. Pengamatan Perkembangan Psikomotorik pada Jenjang Sekolah Menengah Pertama Kota Metro

\begin{tabular}{|c|c|c|c|}
\hline \multirow{7}{*}{$\begin{array}{c}\text { No. } \\
1\end{array}$} & Identitas & Deskripsi Hasil Observasi & \multirow{2}{*}{$\frac{\text { Skor }}{4}$} \\
\hline & \multirow{6}{*}{$\begin{array}{lr}\text { atha } & \text { Dwi } \\
\text { Ningrum, } & 13 \\
\text { tahun, } & \text { SMP } \\
\text { Kartikatama. }\end{array}$} & $\begin{array}{l}\text { Observasi 1, Mampu membuat tulisan arab dengan baik } \\
\text { dan rapih (P2) }\end{array}$ & \\
\hline & & $\begin{array}{l}\text { mampu melakukan oahraga atlentik seperti lari dan } \\
\text { melompat dengan baik (P3) }\end{array}$ & 4 \\
\hline & & $\begin{array}{l}\text { Observasi 2, Menggambar peta dengaan baik dan rapih } \\
\text { (P2) }\end{array}$ & 4 \\
\hline & & Belum mampu menggunakan skiping dengan baik (P3) & 3 \\
\hline & & $\begin{array}{l}\text { Observasi 3, Mengkomunikasikan hasil diskusi di depan } \\
\text { kelas dengan baik (P2) }\end{array}$ & 4 \\
\hline & & Memainkan bola volly tetapi belum mahir (P3) & 3 \\
\hline \multirow[t]{6}{*}{2} & \multirow{6}{*}{$\begin{array}{l}\text { Bagas Eka } \\
\text { Prabowo, } 14 \\
\text { tahun, SMP } \\
\text { Kartikatama. }\end{array}$} & $\begin{array}{l}\text { Observasi 1, Dapat membuat tulisan arab tetapi tidak } \\
\text { rapih (P2) }\end{array}$ & 2 \\
\hline & & Mahir menggunakan skiping (P3) & 3 \\
\hline & & $\begin{array}{l}\text { Observasi 2, Menggambar peta dengaan baik dan rapih } \\
\text { (P2) }\end{array}$ & 4 \\
\hline & & $\begin{array}{l}\text { Memainkan bola basket dengan mahir dan bisa } \\
\text { memasukannya ke ring (P3) }\end{array}$ & 4 \\
\hline & & $\begin{array}{l}\text { Observasi 3, Mampu mengidentifikasi hasil pengamatan } \\
\text { tumbuhan dengan baik (P2) }\end{array}$ & 4 \\
\hline & & $\begin{array}{l}\text { Sudah dapat menggunakan mikroskop tetapi masih di } \\
\text { bantu oleh guru (P3) }\end{array}$ & 3 \\
\hline \multirow[t]{6}{*}{3} & \multirow{6}{*}{$\begin{array}{l}\text { Iqbal Adi } \\
\text { Prastyo, } 14 \text { tahun } \\
\text { SMP Ma'arif } 1 \\
\text { Metro. }\end{array}$} & $\begin{array}{l}\text { Observasi 1, Mampu menggambar alat ekskresi dengan } \\
\text { baik (P2) }\end{array}$ & 4 \\
\hline & & $\begin{array}{l}\text { Mahir menggunakan Hanphone untuk browsing materi } \\
\text { pelajaran (P3) }\end{array}$ & 4 \\
\hline & & $\begin{array}{l}\text { Observasi 2, Membuat karangan tentang latar munculnya } \\
\text { nasionalisme Indonesia dengan baik (P2) }\end{array}$ & 4 \\
\hline & & $\begin{array}{l}\text { Menggunakan sepak bola besar untuk olahraga cukup } \\
\text { mahir (P3) }\end{array}$ & 3 \\
\hline & & $\begin{array}{l}\text { Observasi 3, Membuat surat dinas dengan melihat } \\
\text { panduan }(\mathrm{P} 2)\end{array}$ & 3 \\
\hline & & $\begin{array}{l}\text { Menjelaskan urutan sistem pencernanan menggunkan } \\
\text { torso dengan tepat }(\mathrm{P} 3)\end{array}$ & 4 \\
\hline \multirow[t]{6}{*}{4} & \multirow{6}{*}{$\begin{array}{l}\text { Tina Restiana, } 13 \\
\text { tahun SMP } \\
\text { Ma'arif } 1 \text { Metro. }\end{array}$} & $\begin{array}{l}\text { Observasi 1, Mampu menggambar tata surya sesuai } \\
\text { dengan urutannya (P2) }\end{array}$ & 4 \\
\hline & & Mampu menggunakan gitar sebagai media kesenian (P3) & 4 \\
\hline & & $\begin{array}{l}\text { Observasi 2, Menggambar bangun jajar genjang dengan } \\
\text { rapih (P2) }\end{array}$ & 4 \\
\hline & & Menggunakan raket dengan lincah (P3) & 4 \\
\hline & & $\begin{array}{l}\text { Observasi 3, Membuat surat izin dan surat dinas dengan } \\
\text { baik dan tepat (P2) }\end{array}$ & 4 \\
\hline & & $\begin{array}{l}\text { Dapat mengunakan media pianika tetapi belum lancar } \\
\text { (P3) }\end{array}$ & 4 \\
\hline \multirow[t]{6}{*}{5} & \multirow{6}{*}{$\begin{array}{l}\text { Dwiky Bima } \\
\text { Nurfasa, 13 } \\
\text { tahun, SMP N } 4 \\
\text { Metro }\end{array}$} & $\begin{array}{l}\text { Observasi 1, Aktif saat berdiskusi dengan teman-teman } \\
\text { (P2) }\end{array}$ & 4 \\
\hline & & Lancar bermain bulu tangkis (P3) & 4 \\
\hline & & $\begin{array}{l}\text { Observasi 2, Membuat tugas hasil pengamatan dengan } \\
\text { baik (P2) }\end{array}$ & 4 \\
\hline & & $\begin{array}{l}\text { Menjelaskan organ-organ penceranan menggunakan to } \\
\text { rso dengan baik (P3) }\end{array}$ & 4 \\
\hline & & $\begin{array}{l}\text { Observasi 3, mengkomunikasikan hasil pengamatan } \\
\text { cukup baik (P2) }\end{array}$ & 3 \\
\hline & & Menggunakan gitar dengan lancar (P3) & 4 \\
\hline
\end{tabular}




\begin{tabular}{cllc}
\hline 6 & $\begin{array}{l}\text { Vega Amelia } \\
\text { Putri, 14 tahun, } \\
\text { SMP N 4 Metro }\end{array}$ & $\begin{array}{l}\text { Observasi 1, Aktif saat berdiskusi dengan teman-teman } \\
\text { (P2) }\end{array}$ & 4 \\
\cline { 2 - 3 } & Tidak terlalu lancar bermain bulu tangkis (P3) & 2 \\
\cline { 2 - 3 } & $\begin{array}{l}\text { Observasi 2, Membuat tugas hasil pengamatan dengan } \\
\text { baik (P2) }\end{array}$ & 4 \\
\cline { 2 - 3 } & $\begin{array}{l}\text { Menjelaskan organ-organ penceranan menggunakan torso } \\
\text { cukup baik (P3) }\end{array}$ & 3 \\
\cline { 2 - 3 } & $\begin{array}{l}\text { Observasi 3, Mengkomunikasikan hasil pengamatan } \\
\text { cukup baik (P2) }\end{array}$ & 3 \\
\cline { 2 - 3 } & \multicolumn{1}{c}{ Dapat memainkan pianika tetapi dengan perlahan (P3) } & 3 \\
\hline & \multicolumn{1}{c}{ Rata-Rata } & 3,61 \\
\hline
\end{tabular}

Tabel 4. Pengamatan Perkembangan Psikomotorik pada Jenjang Sekolah Menengah Atas Kota Metro

\begin{tabular}{|c|c|c|c|}
\hline No. & Identitas & Deskripsi Hasil Observasi & Skor \\
\hline \multirow[t]{6}{*}{1} & \multirow{6}{*}{$\begin{array}{l}\text { Made Merta, } 17 \\
\text { tahun, SMA N } 3 \\
\text { Metro. }\end{array}$} & $\begin{array}{l}\text { Observasi 1, Membuat karya sebuah gambar dengan } \\
\text { bagus (P2) }\end{array}$ & 4 \\
\hline & & $\begin{array}{l}\text { Menggunakan pencil khusus untuk menggambar dengan } \\
\text { baik dan mewarnai dengan kuas warna dengan rapih (P3) }\end{array}$ & 4 \\
\hline & & Observasi 2, berdiskusi aktif dalam kelompok (P2) & 4 \\
\hline & & $\begin{array}{l}\text { Mampu mengoprasikan peralatan basket dengan baik dan } \\
\text { benar 5x bola masuk ke ring dalam } 30 \text { detik (P3) }\end{array}$ & 3 \\
\hline & & $\begin{array}{l}\text { Observasi 3, Membuat suatu data atau grafik dengan } \\
\text { baik dan benar (P2) }\end{array}$ & 4 \\
\hline & & $\begin{array}{l}\text { Mampu mengoprasikan aplikasi komputer sepperti } \\
\text { perangkat microsoft excel dengan baik dan benar (P3) }\end{array}$ & 4 \\
\hline \multirow[t]{6}{*}{2} & \multirow{6}{*}{$\begin{array}{l}\text { Robi Satria, } 16 \\
\text { tahun, SMA N } 3 \\
\text { Metro. }\end{array}$} & $\begin{array}{l}\text { Observasi 1, Membuat suatu karya Saat membuat } \\
\text { gambar masih belum terlalu bagus (P2) }\end{array}$ & 3 \\
\hline & & $\begin{array}{l}\text { Menggunakan pencil khusus untuk menggambar dengan } \\
\text { baik dan mewarnai dengan kuas warna dengan rapih (P3) }\end{array}$ & 4 \\
\hline & & Observasi 2, berdiskusi aktif dalam kelompok (P2) & 4 \\
\hline & & $\begin{array}{l}\text { Mampu mengoprasikan peralatan basket dengan baik dan } \\
\text { benar } 7 x \text { bola masuk ke ring dalam } 30 \text { detik (P3) }\end{array}$ & 4 \\
\hline & & $\begin{array}{l}\text { Observasi 3, Membuat suatu data atau grafik dengan } \\
\text { baik dan benar (P2) }\end{array}$ & 4 \\
\hline & & $\begin{array}{l}\text { Mengoprasikan aplikasi komputer sepperti perangkat } \\
\text { microsoft excel dengan dipandu teman (P3) }\end{array}$ & 3 \\
\hline \multirow[t]{6}{*}{3} & \multirow{6}{*}{$\begin{array}{l}\text { Zainun Nuriya } \\
\text { Rosyadi, 16 } \\
\text { tahun, SMA TMI } \\
\text { Roudlotul } \\
\text { Qur'an. }\end{array}$} & $\begin{array}{l}\text { Observasi 1, Membuat karya kaligrafi dengan ukiran } \\
\text { halus (P2) }\end{array}$ & 4 \\
\hline & & $\begin{array}{l}\text { Mampu menggunakan Spidol Khusus kaligrafi, Pencil } \\
\text { handam dengan lincah dan benar (P3) }\end{array}$ & 4 \\
\hline & & $\begin{array}{l}\text { Observasi 2, Membuat grafik dari hasil pengamatan } \\
\text { dengan benar (P2) }\end{array}$ & 4 \\
\hline & & $\begin{array}{l}\text { Mampu mengoperasikan aplikasi ms. Excel dengan baik } \\
\text { dan benar (P3) }\end{array}$ & 4 \\
\hline & & $\begin{array}{l}\text { Observasi 3, Membuat suatu puisi yang sesuai dengan } \\
\text { kaidah penulisan (P2) }\end{array}$ & 4 \\
\hline & & $\begin{array}{l}\text { Menggunakan properti tambahan dengan baik saat } \\
\text { membacakan puisi (P3) }\end{array}$ & 4 \\
\hline 4 & $\begin{array}{l}\text { Eva Anggun, } 16 \\
\text { tahun, SMA TMI }\end{array}$ & $\begin{array}{l}\text { Observasi 1, Membuat karya kaligrafi kurang rapih dan } \\
\text { belum halus (P2) }\end{array}$ & 2 \\
\hline
\end{tabular}




\begin{tabular}{|c|c|c|c|}
\hline & \multirow[t]{5}{*}{$\begin{array}{l}\text { Roudlotul } \\
\text { Qur'an. }\end{array}$} & $\begin{array}{l}\text { Belum lancar menggunakan spidol kaligrafi dan pencil } \\
\text { handam (P3) }\end{array}$ & 2 \\
\hline & & $\begin{array}{l}\text { Observasi 2, Membuat grafik dari hasil pengamatan } \\
\text { dengan benar (P2) }\end{array}$ & 4 \\
\hline & & $\begin{array}{l}\text { Mampu mengoperasikan aplikasi ms. Excel dengan baik } \\
\text { dan benar (P3) }\end{array}$ & 4 \\
\hline & & $\begin{array}{l}\text { Observasi 3, Membuat suatu puisi yang sesuai dengan } \\
\text { kaidah penulisan }(\mathrm{P} 2)\end{array}$ & 4 \\
\hline & & $\begin{array}{l}\text { Menggunakan properti tambahan dengan baik saat } \\
\text { membacakan puisi }(\mathrm{P} 3)\end{array}$ & 4 \\
\hline \multirow[t]{6}{*}{5} & \multirow{6}{*}{$\begin{array}{l}\text { Zainudin } \\
\text { Kurniawan, } 15 \\
\text { tahun, SMK } \\
\text { Muhammadiyah } \\
1 \text { Metro. }\end{array}$} & $\begin{array}{l}\text { Observasi 1, Memimpin diskusi, bertanya, dan } \\
\text { mengutarakan pendapat kurang lancar (P2) }\end{array}$ & 3 \\
\hline & & $\begin{array}{l}\text { Mengoperasikan perangkat kerja microsoft word dengan } \\
\text { baik (P3) }\end{array}$ & 4 \\
\hline & & $\begin{array}{l}\text { Observasi 2, Membuat tugas tentang pergaulan sosial } \\
\text { dengan baik (P2) }\end{array}$ & 4 \\
\hline & & $\begin{array}{l}\text { Mengoperasikan perangkat kerja microsoft excel kurang } \\
\text { lancar (P3) }\end{array}$ & 3 \\
\hline & & $\begin{array}{l}\text { Observasi 3, Mengkomunikasikan presentasi kinerja } \\
\text { dengan baik dan lancar (P2) }\end{array}$ & 4 \\
\hline & & Mengoperasikan perangkat kerja Ppt dengan baik (P3) & 4 \\
\hline \multirow[t]{8}{*}{6} & \multirow{6}{*}{$\begin{array}{l}\text { Wahyu Arif } \\
\text { Budiman, } 16 \\
\text { tahun, SMK } \\
\text { Muhammadiyah } \\
1 \text { Metro }\end{array}$} & $\begin{array}{l}\text { Observasi 1, Memimpin diskusi, bertanya, dan } \\
\text { mengutarakan pendapat dengan baik (P2) }\end{array}$ & 4 \\
\hline & & $\begin{array}{l}\text { Mengoperasikan perangkat kerja microsoft word dengan } \\
\text { baik (P3) }\end{array}$ & 4 \\
\hline & & $\begin{array}{l}\text { Observasi 2, Membuat tugas tentang pergaulan sosial } \\
\text { dengan baik (P2) }\end{array}$ & 4 \\
\hline & & $\begin{array}{l}\text { Mengoperasikan perangkat kerja microsoft excel dengan } \\
\text { baik (P3) }\end{array}$ & 4 \\
\hline & & $\begin{array}{l}\text { Observasi 3, Mengkomunikasikan presentasi kinerja } \\
\text { dengan baik tetapi kurang lancar (P2) }\end{array}$ & 3 \\
\hline & & Mengoperasikan perangkat kerja Ppt dengan baik (P3) & 4 \\
\hline & & Rata-Rata & 3,72 \\
\hline & & Persentase & $93 \%$ \\
\hline
\end{tabular}

Tabel 5. Skala Likert

\begin{tabular}{c|l|c}
\hline No & Ket. skala penilaian & Skor \\
\hline 1 & Sangat Baik (SB) & 4 \\
\hline 2 & Baik (B) & 3 \\
\hline 3 & Tidak Baik (TB) & 2 \\
\hline 4 & $\begin{array}{l}\text { Sangat Tidak Baik } \\
\text { (STB) }\end{array}$ & 1 \\
\hline
\end{tabular}

Tabel 6. Kriteria Interprestasi Skor

\begin{tabular}{l|l}
\hline Persentase & Kriteria \\
\hline $0 \%-20 \%$ & Sangat Lemah \\
\hline $21 \%-40 \%$ & Lemah \\
\hline $41 \%-60 \%$ & Cukup \\
\hline $61 \%-80 \%$ & Kuat \\
\hline $81 \%-100 \%$ & Sangat Kuat \\
\hline
\end{tabular}

Sumber: Riduwan (2010:18)

Dari hasil observasi perkembangan psikomotorik peserta didik di atas rata-rata interprestasi
Skor memperoleh kriteria Sangat kuat yaitu TK 91, 75\%, SD 89,5\%, SMP $90,25 \%$, dan SMA 93\%. Pada dasarnya peserta didik memiliki kemampuan yang baik dalam aspek keterampilan atau psikomotorik di setiap jenjang dan usianya. Fase perkembangan pada umumnya dapat dibagi menjadi tiga antara lain; 1) 0 7 tahun (masa kanak-kanak), 7 -14 tahun (masa anak sekolah), dan 14 21 tahun (masa pubertas).

Perkembangan

anak ditentukan oleh beberapa faktor, yaitu: 1) pembawaan yang dibawa sejak lahir, 2) lingkungan atau pendidikan dan pengalamannya yang diterimasejak kecil dan oleh pembawaan dan lingkungan. 
Sedangkan cara pembelajaran yangakan dipergunakan sebaiknya menyesuaikan dengan kondisi/ tingkatan yang ada pada anak agar anak dengan mudah memahami materi yang diberikan(Samiudin, 2017).

Aspek psikomotor merupakan salah satu aspek yang penting untuk diketahui oleh guru. Kemampuan psikomotor berkaitan dengan keterampilan motorik yang berhubungan dengan anggota tubuh atau tindakan yang memerlukan koordinasi antara syaraf dan otak. Kemampuan ini dapat dikelompokkan menjadi lima, yaitu meniru, memanipulasi, akurasi gerak, artikulasi dan naturalisasi / otonomisasi (Samiudin, 2017).

$$
\text { Indikator }
$$

membuat/mengkomunikasikan suatu karya dan (P3) Mengoperasikan suatu alat/benda secara tidak langsung selalu ada dalam keseharian kegiatan pembelajaran. Guru hanya perlu memahami tingkatan kompetensi psikomotorik agar dapat mengembangkan indikator sesuai KKO yang terdapat dalam masingmasing tingkatan. Setelah itu, guru juga harus dapat memilih metode pembelajaran yang tepat agar kompetensi psikomotor peserta didik dapat berkembang dengan baik.

$$
\text { Metode atau model }
$$

pembelajaran yang dapat
mengembangkan psikomotorik siswa antara lain; Pembelajaran keterampilan vokasional (pengabungan teori dan praktik) yang berorientasi pada pembuatan hasil karya dan produk yang dihasilkan dapat meningkatkan kompetensi keterampilan dan sikap peserta didik (Lia et. al., 2017). Pembelajaran kooperatif juga membuat anak dapat berkelompok dan berdiskusi dengan luwes dalam pembelajaran. Penelitian Marfuah (2017), menghasilkan temuan bahwa keterampilan komunikasi peserta didik meningkat dengan mengunakan model pembelajaran Kooperatif tipe Jigsaw. Penggunaan metode pembelajaran tutor sebaya berkontribusi terhadap peningkatan keterampilan menggunakan atau mengoperasikan suatu alat, paradigma yang melandasi dikembangkannya metode tersebut adalah siswa akan lebih cepat memahami apa yang diajarkan oleh temannya, dibandingkan dengan apa yang diajarkan oleh guru. Hasil penelitian Hendriansyah (2013) menunjukan bahwa pembelajaran dengan tutor sebaya terbukti dapat meningkatkan keterampilan siswa dalam bermain ornamen suling lubang enam, baik dari posisi duduk, posisi lidah dan posisi bibir, perpindahan jari, teknik pernafasan dan penciptaan variasi bunyi serta mampu menciptakan pembelajaran yang berpusat pada siswa (student centered).

\section{KESIMPULAN}

Kegiatan-kegiatan psikomotor yang sering diterapkan dalam proses pembelajaran dan sesuai dengan tingkatan perkembangan psikomotorik adalah Tingkatan ke-2 dan ke-3; yaitu 1) manipulasi (P2) adalah kemampuan melakukan kegiatan sederhana yang belum pernah dilihat sebelumnya tetapi berdasarkan pedoman atau petunjuk saja. Indikator yang diamati (P2) membuat/mengkomunikasikan suatu karya KKO lain yang dapat digunakan adalah mendemonstrasikan, melatih, dan merancang. 2) pengalamiahan 
(naturalisasi) (P3) adalah kemampuan melakukan kegiatan secara refleks, yakni kegiatan yang melibatkan fisik saja sehingga efektivitas kerja tinggi. indikator yang diamati (P3) Mengoperasikan suatu alat/benda. KKO lain yang dapat digunakan adalah memindahkan, mendorong, menarik, memproduksi, dan memutar. Model pembelajaran yang dapat mengembangkan psikomotor tingkat P2 adalah model pembelajaran vokasional dan kooperatif, untuk psikomotor P3 dapat dikembangkan dengan model pembelajaran tutor sebaya.

\section{SARAN}

Pendidik terutama guru dapat mengembangkan kegiatatan psikomotorik peserta didik dalam proses pembelajaran dengan mendesain Rencana Pelaksanaan Pembelajaran dan instrumen penilaian psikomotorik sesuai dengan indikator yang dikembangkan berdasarkan teori tingktan psikomotor peserta didik dengan tepat. Penelitian selanjutnya, peneliti dapat mengembangkan desain pembelajaran yang dapat meningkatkan kinerja pendidik atau calon pendidik (mahasiswa) untuk dapat mendesain pembelajaran berbasis kurikulum yang sedang diterapkan masa kini.

\section{DAFTAR RUJUKAN}

Asih, Triana. 2018. Model Panduan Pembelajaran Psikomotorik Biologi. Metro: Laduny.

Asih, Triana., Khayuridlo, M., dan Noor, Rasuane. 2018. Analisis
Pembelajaran Saintifik dan

Ranah Psikomotorik melalui

Modul Praktikum Makro Alga.

Makalah di sajikan dalam

Seminar Nasional Pendidikan MIPA FKIP Unila.

Meningkatkan Mutu

Pembelajaran Matematika dan Ilmu Pengetahuan Alam di Era Revolusi 4.0. Unila, Bandar Lampung, 3 November 2018.

Aziz, Farhan., Nurjanah, Fajrin., Sari, Dyah Permata. 2017. Aktualisasi TTB (Teori Taksonomi Bloom) melalui Drama Kepahlawanan Guna Penanaman Pendidikan Karakter pada Peserta Didik. Makalah disajikan dalam Seminar PS PBSI Universitas Jember \#4 Eksplorasi Bahasa Sastra dan Budaya Jawa Timuran sebagai Upaya Penguatan Pendidikan Berbasis Ekologi., Universitas Jember, Jember, 22 Maret.

Hendriansyah, Dede., Milyartini, Rita., Kurdita, Engkur. 2013. Penerapan Metode Pembelajaran Tutor Sebaya Dalam Meningkatkan Keterampilan Bermain Ornamen Suling Lubang Enam. Jurnal Antologi Departemen Pendidikan Seni Musik FPSD UPI. 1(3), 1-17.

Kemendikbud. 2016. Permendikbud 22 Tahun 2016 tentang Standar Proses. Jakarta : Kementrian Pendidikan dan Kebudyaan.

Lia, Natalia., Syamwil, Rodia., dan Widayani, Sus. 2017. Model Pembelajaran Keterampilan 
Vokasional Berbasis Potensi

Lokal di SMA Wilayah

Kalimantan. Journal of

Vocational and Career

Educational. 2 (2), (2017) (50-

58).

Marfuah. 2017. Meningkatkan

Keterampilan Komunikasi

Peserta Didik melalui Model

Pembelajaran Kooperatif Tipe

Jigsaw. Jurnal Pendidikan

Ilmu Sosial. 26(2), 148-160.

Riduwan. 2010. Rumus dan Data

dalam Analisis Statistika.

Bandung: Alfabeta.

Samiudin. 2017. Pentingnya

Memahami Perkembangan

Anak Untuk Menyesuaikan

Cara Mengajar Yang

Diberikan. PANCAWAHANA:

Jurnal Studi Islam. 12(1),1-9. 